The Journal of Bone E Joint Surgery
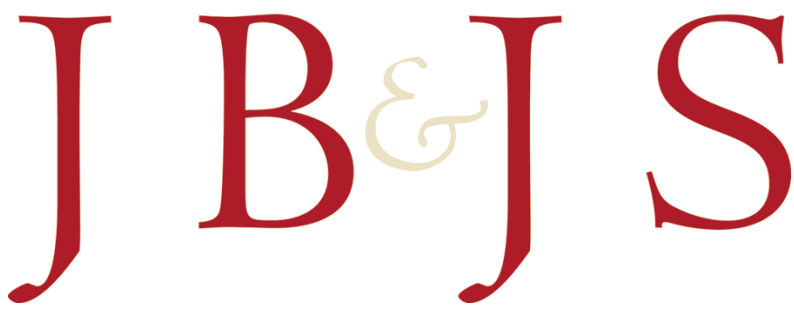

This is an enhanced PDF from The Journal of Bone and Joint Surgery

The PDF of the article you requested follows this cover page.

\title{
Cost-Utility Analyses in Orthopaedic Surgery
}

Carmen A. Brauer, Allison B. Rosen, Natalia V. Olchanski and Peter J. Neumann J Bone Joint Surg Am. 2005;87:1253-1259. doi:10.2106/JBJS.D.02152

This information is current as of January 18, 2011

Supplementary Material

Reprints and Permissions

Publisher Information
http://www.ejbjs.org/cgi/content/full/87/6/1253/DC1

Click here to order reprints or request permission to use material from this article, or locate the article citation on jbjs.org and click on the [Reprints and Permissions] link.

The Journal of Bone and Joint Surgery

20 Pickering Street, Needham, MA 02492-3157

www.jbjs.org 


\title{
Cost-Utility Analyses in Orthopaedic SURgery
}

\author{
By CARMEN A. Brauer, MD, MSC, FRCSC, ALLison B. Rosen, MD, SCD, \\ Natalia V. OlChanski, MS, AND Peter J. Neumann, SCD \\ Investigation performed at Harvard Center for Risk Analysis, Harvard School of Public Health, Boston, Massachusetts
}

\begin{abstract}
Background: The rising cost of health care has increased the need for the orthopaedic community to understand and apply economic evaluations. We critically reviewed the literature on orthopaedic cost-utility analysis to determine which subspecialty areas are represented, the cost-utility ratios that have been utilized, and the quality of the present literature.
\end{abstract}

Methods: We searched the English-language medical literature published between 1976 and 2001 for orthopaedicrelated cost-utility analyses in which outcomes were reported as cost per quality-adjusted life year. Two trained reviewers independently audited each article to abstract data on the methods and reporting practices used in the study as well as the cost-utility ratios derived by the analysis.

Results: Our search yielded thirty-seven studies, in which 116 cost-utility ratios were presented. Eleven of the studies were investigations of treatment strategies in total joint arthroplasty. Study methods varied substantially, with only five studies (14\%) including four key criteria recommended by the United States Panel on Cost-Effectiveness in Health and Medicine. According to a reader-assigned measure of study quality, cost-utility analyses in orthopaedics were of lower quality than those in other areas of medicine $(p=0.04)$. While the number of orthopaedic studies has increased in the last decade, the quality did not improve over time and did not differ according to subspecialty area or journal type. For the majority of the interventions that were studied, the cost-utility ratio was below the commonly used threshold of $\$ 50,000$ per quality-adjusted life year for acceptable cost-effectiveness.

Conclusions: Because of limitations in methodology, the current body of literature on orthopaedic cost-utility analyses has a limited ability to guide policy, but it can be useful for setting priorities and guiding research. Future research with clear and transparent reporting is needed in all subspecialty areas of orthopaedic practice.

Level of Evidence: Economic and decision analysis, Level III. See Instructions to Authors for a complete description of levels of evidence.

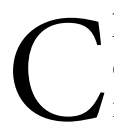
linical programs for patients with musculoskeletal disorders are faced with numerous harsh realities: an aging population requiring more medical intervention, rapidly emerging newer and often more expensive technologies, and fixed budgets. Economic evaluation of orthopaedic surgical treatments is an important area of study that requires high-quality information if it is to be useful to surgeons and policy makers.

Cost-utility analysis is a type of economic analysis that is used to assess the value of an intervention in terms of improving both quality and quantity of life. (This term as well as many others used in this field is defined in a glossary at the end of this article.) "Utility" refers to an individual's or society's preference for a particular set of health outcomes. Many tools have been developed to aid researchers in estimating a patient's preference for a specific health state, which is then used to calculate quality of life. These tools include generic instruments (e.g., the EQ-5D ${ }^{1}$, the Health Utilities Index [HUI $]^{2}$, and the Quality of Well Being [QWB] Index ${ }^{3}$, which link information from general questionnaires with separately derived preferences for health states, and direct measurement techniques, with which a group of subjects is asked directly to provide information about their preferences for a set of health states with use of time-trade-off, standard-gamble, or ratingscale methods (see Glossary). The goal of all of these approaches is to derive measures that can then be used in utility and cost-utility analyses.

Cost-utility analysis is useful for comparing health treatments or programs that may differ in terms of their effects on morbidity as opposed to only mortality. The incremental cost of an intervention is compared with the incremental health effects of the intervention, and the result usually is expressed as a cost per quality-adjusted life year gained (see Glossary). By combining quality and duration of life into a single metric, the qualityadjusted life year allows for comparisons across a broad array of interventions for the same condition and across different condi- 
The Journal of Bone \& JOINT SURgery • JBIS. ORG VOLUme 87-A · Number 6 · JUNE 2005

tions. Consequently, cost-utility analysis is considered the gold standard for reporting the results of economic evaluations in the medical literature ${ }^{4-7}$.

We are not aware of any systematic and comprehensive audits of the cost-utility literature in orthopaedics. We therefore conducted a systematic review of original cost-utility analyses of orthopaedic surgery in the medical literature. Our objectives were (1) to provide a resource listing published cost-utility ratios that can be used by clinicians and policy makers for decision-making, (2) to identify areas within orthopaedic surgery that may benefit from further economic evaluation, and (3) to critically review the conduct and reporting of cost-utility analyses of orthopaedic surgery to identify opportunities for improvement as these studies play an increasing role in informing health policy decisions.

\section{Materials and Methods}

$\Upsilon$ his study was part of a larger study in which all cost-utility analyses in medicine were reviewed ${ }^{8,9}$. Study details, including information on the cost-utility ratios ${ }^{9}$, utility values ${ }^{10}$, and reporting practices ${ }^{8}$, are described elsewhere in detail, and a comprehensive registry of these studies is available as a public-use data file at www.hsph.harvard.edu/cearegistry.

As part of this larger study, a computerized search restricted to the English-language literature was performed with use of the medical subject headings and/or text keywords "quality-adjusted," "QALY," and "cost-utility." The search was conducted with use of Medline, for the years 1976 through 2001. We validated our search findings with use of the Health Economic Evaluations Database maintained by the British Office of Health Economics ${ }^{11}$. One of us (C.A.B.) then reviewed the articles to determine whether they were orthopaedicrelated and appropriate for inclusion. Two trained reviewers independently abstracted data on whether or not the intervention, comparison, study perspective, and funding source were clearly defined; on the utility measurement technique and source; on whether or not incremental analyses, discounting, and sensitivity analyses were appropriately reported; and on the collection and presentation of the cost data and the costutility ratios (see Glossary). The journals were divided into three groups: general medical or surgical, medical or surgical subspecialty, and methods or policy. The reviewers met to reach a consensus on the results, and a third reviewer adjudicated any discrepancies.

The quality of each paper was subjectively rated on a 7 -point Likert scale on the basis of criteria derived from selected recommendations of the United States Panel on CostEffectiveness in Health and Medicine ${ }^{5,6}$. The panel recommended the use of a societal perspective, community or patient sources for utility estimates, appropriate incremental comparisons, sensitivity analysis, and appropriate discounting of costs and health benefits at the same rate ${ }^{5.6}$. To allow comparisons across countries and between different years, all cost-utility ratios were converted into real 2002 United States dollars with use of the foreign exchange factor (Federal Reserve Bank of St. Louis, St. Louis, Missouri) appropriate to each particular coun-
COST-UTILITY ANALYSES IN

ORTHOPAEDIC SURGERY

try for each particular year and with use of the general Consumer Price Index inflator from the United States Bureau of Labor Statistics. Cost-utility ratios were rounded off to twodigit precision. An unpaired Student t test assuming unequal variances was used to compare group means, and the Fisher exact test was used for comparisons between proportions.

A table was constructed that included a description of each intervention, the alternative with which it was compared, and the appropriate target population. This table was sorted by level of cost-utility, which was divided into five categories: (1) cost-saving (in terms of money and benefit), (2) cost-utility ratio of $<\$ 20,000$ per quality-adjusted life year (considered to be an excellent value for money-i.e., very cost-effective), (3) cost-utility ratio between $\$ 20,000$ and $\$ 100,000$ per quality-adjusted life year (generally considered to be a good value), (4) cost-utility ratio of $>\$ 100,000$ per quality-adjusted life year (not the best value, but many interventions with such a ratio are still funded), and (5) dominated (the intervention is less effective and more costly than the alternative).

\section{Results}

ur search revealed thirty-seven studies of interventions dealing with the musculoskeletal system and orthopaedic surgery published between 1989 and 2001, and these analyses provided a total of 116 cost-utility ratios. Table I lists the characteristics of these articles.

Total joint arthroplasty was the most commonly studied intervention. Of the eleven studies dealing with this subject, five were investigations of the cost-utility of primary total joint arthroplasty (total hip arthroplasty in four articles and total knee arthroplasty in one), three articles dealt with the economic impact of antibiotic prophylaxis for prevention of infection at the site of an arthroplasty, one focused on strategies for managing infections at the site of a total hip arthroplasty, and the remaining two dealt with perioperative issues (autologous blood donation and duplex venous surveillance). Nine articles dealt with osteoporosis prevention with pharmaceutical intervention: three assessed hormone replacement therapy; two, bisphosphonates; one, calcium and vitamin D; and three, other pharmaceutical interventions. Spine surgery was the topic of five papers, with two papers dealing with the management of lumbar disc herniation, one involving lumbar spinal fusion, one dealing with clearance of trauma patients for cervical spine surgery, and one focusing on neurosurgical interventions. The last paper was included because it presented a cost-effectiveness ratio for spinal surgery. One or two papers each represented the remaining orthopaedic subspecialties, with none in pediatric orthopaedics.

Table II lists the key methodological features of the articles, and a more comprehensive table providing the methodological features of each study is presented in the Appendix. Adherence to good methodological practices varied: only nine studies (24\%) dealt with utility from a societal perspective by including some measure of indirect costs (see Glossary). Six of those studies included costs in terms of patient time and/or productivity; one included transportation costs; one, costs in 
The Journal of Bone \& JOINT SURgery • JBIS. ORG Volume 87-A · Number 6 · June 2005
COST-UTILITy ANALYSES IN

ORTHOPAEDIC SURGERY
TABLE I Characteristics of Orthopaedic Cost-Utility Analyses Identified in Literature Review

\begin{tabular}{|c|c|}
\hline Characteristic & $\begin{array}{l}\% \text { of Articles } \\
\quad(\mathrm{N}=37)\end{array}$ \\
\hline \multicolumn{2}{|l|}{ Year of publication } \\
\hline 1989-1997 & 43 \\
\hline $1998-2001$ & 57 \\
\hline \multicolumn{2}{|l|}{ Country of study } \\
\hline United States & 54 \\
\hline Sweden & 19 \\
\hline Canada & 8 \\
\hline United Kingdom & 8 \\
\hline Other* & 11 \\
\hline \multicolumn{2}{|l|}{ Journal type } \\
\hline General medical or surgical & 19 \\
\hline Medical or surgical subspecialty & 62 \\
\hline Methods or policy & 19 \\
\hline \multicolumn{2}{|l|}{ Orthopaedic subspecialty } \\
\hline Total joint arthroplasty & 30 \\
\hline Osteoporosis & 24 \\
\hline Spine & 14 \\
\hline Trauma & 8 \\
\hline Tumor & 5 \\
\hline Foot and ankle & 5 \\
\hline Sports medicine & 5 \\
\hline Hand and upper extremity & 3 \\
\hline Other† & 5 \\
\hline \multicolumn{2}{|l|}{ Sponsorship $\ddagger$} \\
\hline Government & 43 \\
\hline Foundation & 19 \\
\hline $\begin{array}{l}\text { Industry (pharmaceutical or medical } \\
\text { device company) }\end{array}$ & 24 \\
\hline Could not be determined & 27 \\
\hline \multicolumn{2}{|c|}{$\begin{array}{l}\text { *France, Netherlands, Israel, or Australia. †Medical management } \\
\text { of osteoarthritis or health policy. } ¥ \text { More than one response was } \\
\text { allowed for each article. }\end{array}$} \\
\hline
\end{tabular}

terms of caregiver time and productivity; and two, home-care costs. (Two measures of indirect costs were used in one study.) Of the thirty-seven studies, thirteen used a Markov model, which allows for transitions between health states over time. In eighteen studies (49\%) the investigators discounted both costs and health benefits (see Glossary), and in thirty (81\%) they performed incremental analyses, comparing the costs and benefits with those of an alternative therapy.

Studies varied with regard to the reporting of costs and preference weights. The economic data were gathered from a primary source in only seventeen studies (46\%). In most (twenty-one) of the studies, the models of health benefit were based on primary sources, and three of these studies were carried out alongside randomized controlled trials. A number of different methods were used to generate utilities for health states. The authors of most (nineteen) of the studies relied on clinical estimates of utilities, derived from the input of clinicians, decision analysts, experts, or authors without the use of any formal methodology. The time-trade-off or standardgamble technique was used in three studies, and pre-existing generic tools such as the EQ-5D ${ }^{1}$ were employed in eleven. The general community or the patients themselves were the most common sources for utility estimates (twenty-seven studies); health care professionals and/or the authors were the source in fourteen $(38 \%)$.

The mean subjective quality score (assigned on a Likert scale ranging from 1 [low quality] to 7 [high quality]) improved from 3.4 points prior to 1998 to 4.1 points after 1998 ; however, this difference was not significant $(p=0.15)$. There was no difference in the quality of articles among the different journal types (mean scores, 4.5 points for the seven general medical or surgical articles, 3.7 points for the twenty-three orthopaedic subspecialty articles, and 3.0 points for the seven methods or policy articles). The orthopaedic papers had a lower average quality rating (3.7 points) than did the nonorthopaedic cost-utility analyses in our larger database, which had an average quality rating of 4.2 points $(\mathrm{p}=0.04)$. Because these quality ratings were subjectively assigned (albeit by welltrained reviewers), a comprehensive chart of key methodological practices extracted from each article is presented in the Appendix to help readers to independently judge the quality of each study.

Although previous authors have found that studies supported by industry are more likely to yield favorable results ${ }^{12,13}$, we did not find this to be the case for the orthopaedic articles that we reviewed. The industry-funded studies were as likely as the government or foundation-funded studies $(63 \%$ in both cases) to provide cost-utility ratios of $<\$ 50,000$ per qualityadjusted life year (a common threshold below which studies are considered to be cost-effective). Only five articles (one on spine surgery and four on total joint arthroplasty), which presented a total of eight cost-utility ratios, met four key recommendations of the United States Panel on Cost-Effectiveness in Health and Medicine ${ }^{6,714}$ (use of a societal perspective, utility estimates based on community or patient sources, appropriate incremental comparisons, and appropriate discounting of costs and health benefits at the same rate). Of the eight ratios (marked with double asterisks in a table in the Appendix) in these studies, five were $<\$ 50,000$ per quality-adjusted life year (considered to be cost-effective), and none of the articles were funded by industry.

A cost-utility "league table" in the Appendix groups the interventions in the thirty-seven studies into five categories ranging from "cost-saving" (less costly and more effective than the alternative) to "dominated" (more costly and less effective than the alternative). As noted earlier, the lower the cost-utility ratio, the better the value of an intervention as it costs less money to gain a quality-adjusted life year. Eight interventions were cost-saving (cost per quality-adjusted life year of $<\$ 0$ ). Most interventions fell within the ranges of costeffectiveness that have commonly been used as thresholds 
The Journal of Bone \& JOINT SURGERY • JBIS.ORG VOLUme 87-A · Number 6 - JUNE 2005

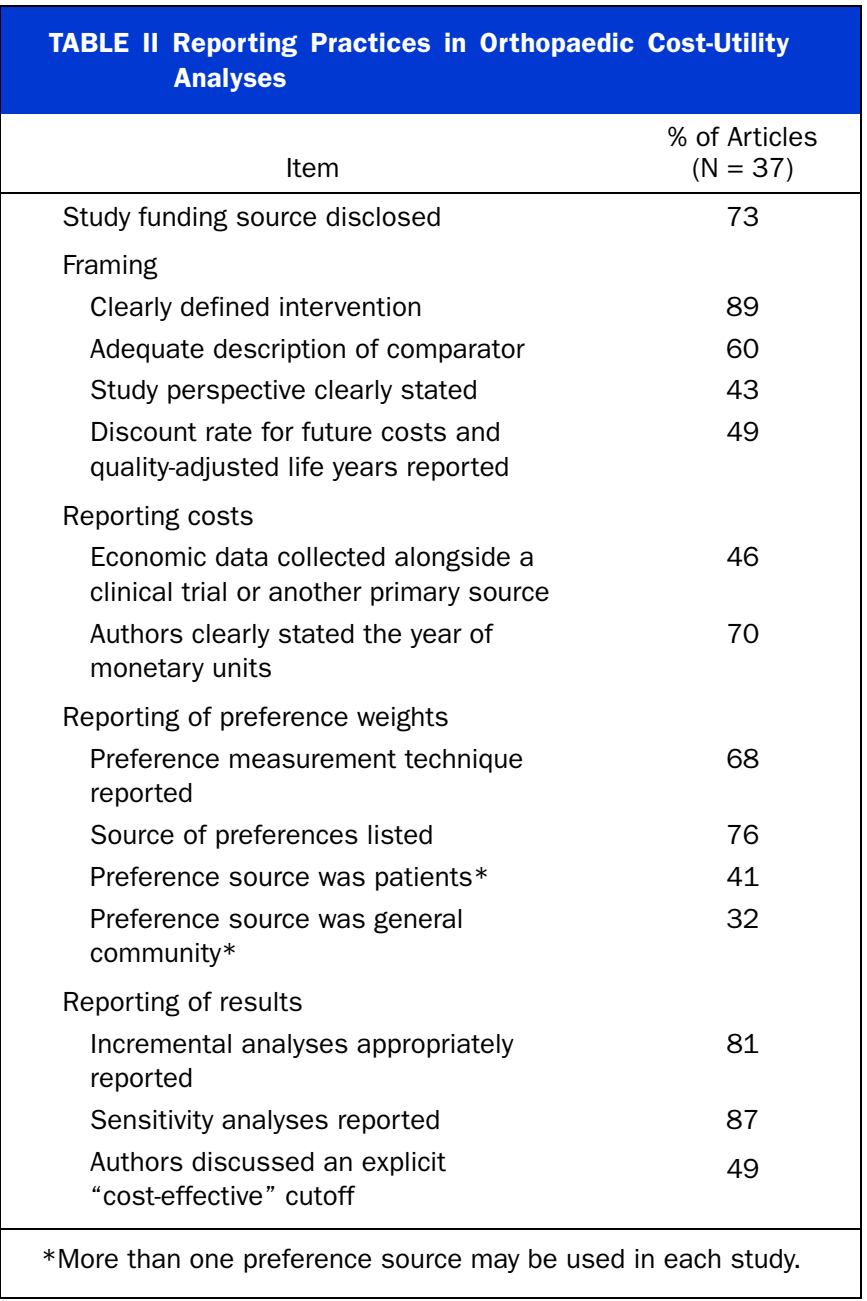

$(\$ 20,000 \text { to } \$ 100,000 \text { Canadian dollars })^{15}$. Thirty-four interventions were estimated to have a cost-utility ratio of $\leq \$ 50,000$, and another nine interventions cost between $\$ 50,000$ and $\$ 100,000$ per quality-adjusted life year. The median was $\$ 15,000$ per quality-adjusted life year.

Several controversial procedures were found to have relatively high cost-utility ratios (i.e., poorer value), including antibiotic prophylaxis in certain situations, venous surveillance with phlebography or ultrasound after total joint replacement, hormone replacement therapy in relatively young patients, and laminectomy with fusion and instrumentation as compared with laminectomy with fusion but no instrumentation in patients with spondylolisthesis and spinal stenosis. Some procedures in common practice, such as the use of bisphosphonates for the treatment of osteoporosis in certain patients and for patients with metastatic breast cancer, had ratios as high as $\$ 360,000$ per quality-adjusted life year, a value usually considered to be cost-ineffective. Autologous blood donation, a common practice in many centers, had a ratio of $\$ 51,000$ per quality-adjusted life year for patients undergoing bilateral or revision total joint replacement in a center with no change in transfusion practices relative to allogeneic blood. In
COST-UTILITY ANALYSES IN

ORTHOPAEDIC SURGERY

a center with increased transfusion of autologous blood (compared with that of allogeneic blood) for patients treated with primary unilateral total hip replacement, the cost-utility ratios of autologous donation ranged from $\$ 310,000$ to $\$ 950,000$ per quality-adjusted life year.

\section{Discussion}

A lhough the volume of published economic evaluations $A$ in the field of orthopaedic surgery is lower than that in other clinical areas, payers are increasingly demanding evidence of cost-effectiveness. This type of research reflects the increasing importance of assessing both the costs and the benefits of an intervention. There has been growth in the number of published economic analyses, and clinicians are being increasingly exposed to these studies. A general understanding of economic evaluations and a specific awareness of the published studies in orthopaedics will be increasingly important to orthopaedic surgeons as they weigh in on reimbursement and other policy decisions that affect the field.

Total joint arthroplasty is the most commonly studied area in the field of orthopaedic surgery. We found six costutility ratios for comparisons of total hip arthroplasty with the alternative of observation only, and all of the ratios are considered to indicate cost-effectiveness (below a threshold value of $\$ 50,000$ per quality-adjusted life year) by today's standards. Osteoporosis is the next most commonly studied area, and, surprisingly, many of the published ratios indicate that treatment may be cost-ineffective. Half of the cost-utility ratios for osteoporosis treatment are $>\$ 100,000$ per quality-adjusted life year. Additional investigation is required as osteoporosis is a major public health problem and it will probably continue to be an area of interest to policy makers.

Spinal surgery, trauma, oncology, pediatric orthopaedics, and sports medicine are underrepresented in the orthopaedic cost-utility-analysis literature. Given the burden of disease and societal costs, there is a need for more information to guide resource allocation decisions within these areas of orthopaedics.

The quality of published cost-utility studies is variable and often poor. The majority of the orthopaedic articles did not clearly define a perspective; $40 \%$ did not explicitly define the comparison; and, in $24 \%$ of the studies, the source of the health-outcome preferences could not be determined. Most authors performed sensitivity analysis, reported the method of cost estimation, discounted appropriately, used incremental analyses, and stated the threshold that they used. Our findings suggest the need for improvement in methodology in several areas. Concerns about the credibility of orthopaedic analyses may persist in the absence of such improvements.

The modified league table in the Appendix allows clinicians and policy makers to quickly view descriptions of the existing cost-utility analyses in orthopaedic surgery in order to assess where the reported cost-effectiveness of an intervention falls. We do not report the actual dollar amount per qualityadjusted life year for each ratio; such exact numbers might be misleading, given the variability of the methods that were used in the studies. The studies in the league table can be examined 
The Journal of Bone \& JOINT SURGERY • JBIS. ORG VOLUme 87-A · Number 6 · JUNE 2005

in the context of the methodological practices (also listed in the Appendix) with which they were performed, allowing the reader to form his or her own judgment about the validity of a study's cost-effectiveness results.

A number of limitations of the present study deserve mention. The search strategy was limited to selected key words, and we only included studies in which the cost-utility ratio was expressed as cost per quality-adjusted life year; therefore, some well-designed studies may have been omitted $^{16-19}$. Reviewers were not blinded to the journal in which the article appeared or to the authors of the article, and this may have biased the results. The merits of the clinical or economic model assumptions were not judged; we sought to determine only whether procedural guidelines for conducting and reporting the analysis were followed. Finally, while the methodological practices varied among the studies, this fact is not reflected in the league table presented in the Appendix. The differences among ratios in league tables can be explained by looking more closely at key elements of each study. Perspective, population, the comparison, the method of utility measurement, the country in which the study was performed, the source of the cost data, and discounting can all affect the resulting ratio. Because of the variability of study methods, the cost-effectiveness ratios presented in league tables must be viewed with caution; they provide an aid to health policy makers but not sufficient evidence on which to base important health policy decisions. We addressed this limitation, to some extent, by placing interventions within a range of costeffectiveness values (rather than providing exact cost-utility ratios) and providing data on study methods for readers who wish to use that information.

Applying economic evaluation methods to orthopaedic interventions is a complex undertaking. It requires several different types of expertise, and a number of methodological issues are still unsettled. There are many interventions that have not yet been studied, and many of those that have been studied need to be investigated further. The aging of the population and the development of newer, more expensive technologies ensure that health care costs will increase. In the past few years, more explicit considerations of costs have come to the fore. In some cases, policy makers have explicitly used cost-effectiveness analysis to make decisions regarding coverage of interventions; however, in most countries in which cost-utility analyses are used in policy making, they are applied to the evaluation of drugs, not devices.

Some private managed-care plans in the United States have developed and used guidelines ${ }^{20}$, and the Centers for Medicare and Medicaid Services have debated the addition of cost-effectiveness analysis to technology assessment; however, the regulation has yet to be finalized. In the United Kingdom, cost-effectiveness analysis is explicitly being used to determine which new technologies should be introduced into the $\mathrm{Na}$ tional Health Service, and this process is not limited to pharmaceuticals. The lack of level-I evidence regarding most interventions in orthopaedic surgery makes it more difficult to perform high-quality cost-utility analyses. In the future, or-
COST-UTILITY ANALYSES IN

ORTHOPAEDIC SURGERY

thopaedists and industry should be encouraged to provide better-quality data for health technology assessment with well-designed prospective, randomized, controlled trials.

There is an urgent need for improving economic evaluation in orthopaedic surgery by using standardized methods and transparent reporting. As the field develops, it will be important to assess both the clinical and the economic assumptions when one reads the economic literature. It also must be emphasized that economic analysis should be used to inform decisions about clinical practice and policy; it should not dictate them ${ }^{14}$.

\section{Appendix}

A table presenting the key methodological criteria of eA each study that was analyzed and a cost-utility league table are available with the electronic versions of this article, on our web site at jbjs.org (go to the article citation and click on "Supplementary Material") and on our quarterly CD-ROM (call our subscription department, at 781-449-9780, to order the CD-ROM).

\section{Glossary}

Definitions are adapted in part from reference 14 .

Cost-utility analysis: A form of economic evaluation that focuses on the quality, not just the quantity, of life resulting from a clinical intervention.

Cost-utility ratio: The ratio is calculated as: (cost of intervention - cost of alternative)/(benefit of intervention - benefit of alternative). Only the ratios expressed as cost per qualityadjusted life year were included in the present study. A lower cost-utility ratio indicates better value. (Less is paid for an increase of one quality-adjusted life year.)

Direct health-care costs: The cost of medical resources consumed (e.g., for physician visits, surgery, and so on).

Discounting: The process of adjusting future costs and future health benefits to their present value. This is done because future costs and benefits are assumed to be worth less to individuals than are present costs and benefits. For example, $\$ 10$ spent during the second year of a patient's treatment is worth less than $\$ 10$ spent in the present. The $\$ 10$ spent in the future needs to be discounted to the present value. If a discount rate of $5 \%$ is used, then the present value would be: $\$ 10 \times[1 /(1+$ $\left.0.05)^{2}\right]=\$ 9.07$.

Generic index of health-related quality of life: A standardized instrument for measuring health outcome that is constructed by determining preferences for various health states with direct measurement techniques such as the time-trade-off, standardgamble, and rating-scale methods. Some commonly used instruments include the EQ-5D ${ }^{1}$, the Health Utilities Index $(\mathrm{HUI})^{2}$, and the Quality of Well Being (QWB) Index ${ }^{3}$.

Incremental cost: The difference between the cost of an intervention and the cost of the alternative with which it is being compared. 
THE JOURNAL OF BONE \& JOINT SURGERY • JBJS.ORG Volume 87-A · Number $6 \cdot$ June 2005
COST-UTILITY ANALYSES IN

ORTHOPAEDIC SURGERY
Indirect costs: Costs such as lost productivity due to time off from work during treatment.

Quality-adjusted life years: A generic outcome derived by using a quality-adjustment weight on the duration of time for which the patient is affected by an intervention. In the conventional approach, the utility (the quality-adjustment weight) is multiplied by the time spent in that health state, and then those values are summed to calculate the number of quality-adjusted life years. For example, if the patient spends one year after the surgery in a state that is $50 \%$ of perfect health (a utility value of 0.5 ) and then has a return to perfect health for the next year, the gain in quality-adjusted life years at two years would be $(0.5 \times 1)+(1 \times 1)=1.5$ quality-adjusted life years.

Sensitivity analysis: Analysis that determines the impact of changing variables on the results (e.g., what effect does changing the hospital costs of an intervention have on the results?).

Standard gamble: A method of determining utility/preference weights. The respondent is asked to compare life in a given suboptimal health state with a gamble between two alternate outcomes: perfect health (denoted as probability $\mathrm{p}$ ) and death (denoted as $1-\mathrm{p}$ ). The probabilities in the gamble are varied until the respondent is indifferent regarding the choice between the given suboptimal health state and the gamble. The utility for the given health state is then calculated as: [ $p \times$ utility (perfect health) $]+[(1-p) \times$ utility (death) $]$. For example, a person may be told that he or she can choose to live for his or her remaining ten years with limited mobility and pain or risk a therapy (perhaps surgery) that may restore perfect health (utility $=1$ ) or cause death (utility $=0$ ). If the risk of death is varied until the person is indifferent regarding the choice between limited mobility and a $15 \%$ chance of death (the gamble), the utility $=(0.85 \times 1)+(0.15 \times 0)$, or 0.85 .

Time trade-off: A method of determining utility/preference weights. The respondent is asked to choose between life in a given suboptimal health state for a fixed amount of time (such as limited mobility for ten remaining years of life) and life in perfect health for a shorter period of time (such as perfect mobility for eight years). The life expectancy in perfect health is varied until the respondent is indifferent regarding the choice between the two states, and the utility is then calculated as: life expectancy in perfect health/life expectancy in suboptimal health (in this example, the utility is $8 / 10$ or 0.8 ).

Utility states (also referred to as "preference weights"): A measure of an individual's or a society's preference for a particular set of health outcomes. For example, if a construction worker and a computer programmer who have sustained a calcaneal fracture are each asked to rank "having a broken foot" on a scale of 0 (defined as death) to 1 (defined as perfect health), their rankings might differ considerably because of the importance that each attaches to the use of the lower limb. Utilities can then be used to calculate quality-adjusted life years by multiplying the utility for a health state by the duration of time spent in that health state. This allows comparison of outcomes (in quality-adjusted life years) across different interventions and different diseases.

Carmen A. Brauer, MD, MSc, FRCSC

Natalia V. Olchanski, MS

Peter J. Neumann, ScD

Harvard Center for Risk Analysis, Harvard School of Public Health, 718

Huntington Avenue, Boston, MA 02115. E-mail address for C.A. Brauer: cbrauer@hsph.harvard.edu

Allison B. Rosen, MD, ScD

Division of General Medicine, University of Michigan Health Systems, Department of Health Management and Policy, University of Michigan School of Public Health and Center for Practice Management and Outcomes Research, Suite 7C27, 300 North Ingalls Street, Ann Arbor, MI 48109

In support of their research or preparation of this manuscript, one or more of the authors received grants or outside funding from the Alberta Heritage Foundation for Medical Research and the Agency for Health Care Research and Quality (Grant RO1 HS 10919). None of the authors received payments or other benefits or a commitment or agreement to provide such benefits from a commercial entity. No commercial entity paid or directed, or agreed to pay or direct, any benefits to any research fund, foundation, educational institution, or other charitable or nonprofit organization with which the authors are affiliated or associated.

doi:10.2106/JBJS.D.02152

\section{References}

1. Brooks R. EuroQol: the current state of play. Health Policy. 1996;37:53-72.

2. Horsman J, Furlong W, Feeny D, Torrance G. The Health Utilities Index (HUI): concepts, measurement properties and applications. Health Qual Life Outcomes. 2003;1:54. www.hqlo.com/content/1/1/54.

3. Kaplan RM, Anderson JP. A general health policy model: update and applications. Health Serv Res. 1988;23:203-35.

4. Russell LB, Gold MR, Siegel JE, Daniels N, Weinstein MC. The role of costeffectiveness analysis in health and medicine. Panel on Cost-Effectiveness in Health and Medicine. JAMA. 1996;276:1172-7.

5. Siegel JE, Weinstein MC, Russell LB, Gold MR. Recommendations for reporting cost-effectiveness analyses. Panel on Cost-Effectiveness in Health and Medicine. JAMA. 1996;276:1339-41.

6. Weinstein MC, Siegel JE, Gold MR, Kamlet MS, Russell LB. Recommendations of the Panel on Cost-Effectiveness in Health and Medicine. JAMA. 1996; 276:1253-8.
7. Gold M. Panel on cost-effectiveness in health and medicine. Med Care. 1996;34(12 Suppl):DS197-9.

8. Neumann PJ, Stone PW, Chapman RH, Sandberg EA, Bell CM. The quality of reporting in published cost-utility analyses, 1976-1997. Ann Intern Med. 2000; 132:964-72.

9. Chapman RH, Stone PW, Sandberg EA, Bell C, Neumann PJ. A comprehensive league table of cost-utility ratios and a sub-table of "panel-worthy" studies. Med Decis Making. 2000;20:451-67.

10. Bell CM, Chapman RH, Stone PW, Sandberg EA, Neumann PJ. An off-the-shelf help list: a comprehensive catalog of preference scores from published costutility analyses. Med Decis Making. 2001;21:288-94.

11. Office of Health Economics and the International Federation of Pharmaceutical Manufacturers' Associations. Health Economic Evaluations Database. www.ohe-heed.com. Accessed June 26, 2002.

12. Neumann PJ, Sandberg EA, Bell CM, Stone PW, Chapman RH. Are pharma- 
The JOURNAL OF BONE \& JOINT SURGERY · JBJS.ORG VOlume 87-A · Number $6 \cdot$ June 2005
COST-UTILity ANALYSES in

ORTHOPAEDIC SURGERY ceuticals cost-effective? A review of the evidence. Health Aff (Millwood). 2000; 19:92-109.

13. Friedberg M, Saffran B, Stinson TJ, Nelson W, Bennett CL. Evaluation of conflict of interest in economic analyses of new drugs used in oncology. JAMA. 1999;282:1453-7.

14. Gold MR, editor. Cost-effectiveness in health and medicine. New York: Oxford University Press; 1996

15. Laupacis A, Feeny D, Detsky AS, Tugwell PX. How attractive does a new technology have to be to warrant adoption and utilization? Tentative guidelines for using clinical and economic evaluations. CMAJ. 1992;146:473-81.

16. Daellenbach HG, Gillespie WJ, Crosbie P, Daellenbach US. Economic appraisal of new technology in the absence of survival data-the case of total hip replacement. Soc Sci Med. 1990;31:1287-93.

17. Gillespie WJ, Pekarsky B, O'Connell DL. Evaluation of new technologies for total hip replacement. Economic modelling and clinical trials. J Bone Joint Surg Br. 1995; 77:528-33.

18. Faulkner A, Kennedy LG, Baxter K, Donovan J, Wilkinson M, Bevan G. Effectiveness of hip prostheses in primary total hip replacement: a critical review of evidence and an economic model. Health Technol Assess. 1998;2:1-133.

19. Fitzpatrick R, Shortall E, Sculpher M, Murray D, Morris R, Lodge M, Dawson J, Carr A, Britton A, Briggs A. Primary total hip replacement surgery: a systematic review of outcomes and modelling of cost-effectiveness associated with different prostheses. Health Technol Assess. 1998;2:1-64.

20. Fry RN, Avey SG, Sullivan SD. The Academy of Managed Care Pharmacy Format for Formulary Submissions: an evolving standard-a Foundation for Managed Care Pharmacy Task Force report. Value Health. 2003;6:505-21.

21. Birkmeyer JD, Goodnough LT, AuBuchon JP, Noordsij PG, Littenberg B. The cost-effectiveness of preoperative autologous blood donation for total hip and knee replacement. Transfusion. 1993;33:544-51.

22. Blackmore CC, Ramsey SD, Mann FA, Deyo RA. Cervical spine screening with CT in trauma patients: a cost-effectiveness analysis. Radiology. 1999; 212:117-25.

23. Brothers TE, Frank CE, Frank B, Robison JG, Elliott BM, Del Schutte H, Merril $\mathrm{KD}$, Friedman RJ. Is duplex venous surveillance worthwhile after arthroplasty? J Surg Res. 1997;67:72-8.

24. Bryan S, Parkin D, Donaldson C. Chiropody and the QALY: a case study in assigning categories of disability and distress to patients. Health Policy. 1991;18:169-85.

25. Chang RW, Pellisier JM, Hazen GB. A cost-effectiveness analysis of total hip arthroplasty for osteoarthritis of the hip. JAMA. 1996;275:858-65.

26. Chung KC, Walters MR, Greenfield ML, Chernew ME. Endoscopic versus open carpal tunnel release: a cost-effectiveness analysis. Plast Reconstr Surg. 1998:102:1089-99.

27. Dranitsaris G, Hsu T. Cost utility analysis of prophylactic pamidronate for the prevention of skeletal related events in patients with advanced breast cancer. Support Care Cancer. 1999;7:271-9.

28. Eckman MH, Greenfield S, Mackey WC, Wong JB, Kaplan S, Sullivan L, Dukes K, Pauker SG. Foot infections in diabetic patients. Decision and cost-effectiveness analyses. JAMA. 1995:273:712-20.

29. Fisman DN, Reilly DT, Karchmer AW, Goldie SJ. Clinical effectiveness and cost-effectiveness of 2 management strategies for infected total hip arthroplasty in the elderly. Clin Infect Dis. 2001;32:419-30.

30. Garellick G, Malchau H, Herberts P, Hansson E, Axelsson H, Hansson T. Life expectancy and cost utility after total hip replacement. Clin Orthop Relat Res. 1998;346:141-51.

31. Geelhoed E, Harris A, Prince R. Cost-effectiveness analysis of hormone replacement therapy and lifestyle intervention for hip fracture. Aust J Public Health 1994;18:153-60.

32. Givon U, Ginsberg GM, Horoszowski H, Shemer J. Cost-utility analysis of tota hip arthroplasties. Technology assessment of surgical procedures by mailed questionnaires. Int J Technol Assess Health Care. 1998;14:735-42.

33. Gottlob CA, Baker CL Jr, Pellissier JM, Colvin L. Cost effectiveness of anterio cruciate ligament reconstruction in young adults. Clin Orthop Relat Res. 1999; 367:272-82

34. Hillner BE, Weeks JC, Desch CE, Smith TJ. Pamidronate in prevention of bone complications in metastatic breast cancer: a cost-effectiveness analysis. J Clin Oncol. 2000;18:72-9.

35. Jacobson JJ, Schweitzer SO, Kowalski CJ. Chemoprophylaxis of prosthetic joint patients during dental treatment: a decision-utility analysis. Oral Surg Oral Med Oral Pathol. 1991;72:167-77.

36. James M, St Leger S, Rowsell KV. Prioritising elective care: a cost utility analysis of orthopaedics in the north west of England. J Epidemiol Community Health. 1996;50:182-9.

37. Jonsson B, Kanis J, Dawson A, Oden A, Johnell O. Effect and offset of effect of treatments for hip fracture on health outcomes. Osteoporos Int. 1999;10:193-9.

38. Jonsson B. Targeting high-risk populations. Osteoporos Int. 1998;8 Suppl 1:S13-6.

39. Jonsson B, Christiansen C, Johnell $O$, Hedbrandt J. Cost-effectiveness of fracture prevention in established osteoporosis. Osteoporos Int. 1995;5:136-42.

40. Jonsson B, Christiansen C, Johnell O, Hedbrandt J, Karlsson G. Costeffectiveness of fracture prevention in established osteoporosis. Scand J Rheumatol Suppl. 1996;103:30-40.

41. Kanis JA, Dawson A, Oden A, Johnell O, de Laet C, Jonsson B. Costeffectiveness of preventing hip fracture in the general female population. Osteopors Int. 2001;12:356-61.

42. Keen JD, Keen RR. The cost-effectiveness of exclusion arteriography in extremity trauma. Cardiovasc Surg. 2001;9:441-7.

43. Keen JD, Dunne PM, Keen RR, Langer BG. Proximity arteriography: costeffectiveness in asymptomatic penetrating extremity trauma. J Vasc Interv Radiol. 2001;12:813-21.

44. Krijnen P, Kaandorp CJ, Steyerberg EW, van Schaardenburg D, Moens HJ, Habbema JD. Antibiotic prophylaxis for haematogenous bacterial arthritis in patients with joint disease: a cost effectiveness analysis. Ann Rheum Dis. 2001;60:359-66

45. Kuntz KM, Snider RK, Weinstein JN, Pope MH, Katz JN. Cost-effectiveness of fusion with and without instrumentation for patients with degenerative spondylolisthesis and spinal stenosis. Spine. 2000;25:1132-9.

46. Launois R, Henry B, Marty JR, Gersberg M, Lassale C, Benoist M, Goehrs JM. Chemonucleolysis versus surgical discectomy for sciatica secondary to lumbar disc herniation. A cost and quality-of-life evaluation. Pharmacoeconomics. 1994; 6:453-63.

47. Lavernia CJ, Guzman JF, Gachupin-Garcia A. Cost effectiveness and quality of life in knee arthroplasty. Clin Orthop Relat Res. 1997;345:134-9.

48. Malter AD, Larson EB, Urban N, Deyo RA. Cost-effectiveness of lumbar discectomy for the treatment of herniated intervertebral disc. Spine. 1996;21: 1048-55.

49. Minas T. Chondrocyte implantation in the repair of chondral lesions of the knee: economics and quality of life. Am J Orthop. 1998;27:739-44.

50. Patrick DL, Ramsey SD, Spencer AC, Kinne S, Belza B, Topolski TD. Economic evaluation of aquatic exercise for persons with osteoarthritis. Med Care. 2001; 39:413-24.

51. Pickard JD, Bailey S, Sanderson $H$, Rees M, Garfield JS. Steps towards costbenefit analysis of regional neurosurgical care. BMJ. 1990;301:629-35.

52. Seguin J, Garber BG, Coyle D, Hebert PC. An economic evaluation of trauma care in a Canadian lead trauma hospital. J Trauma. 1999;47(3 Suppl):S99-103.

53. Solomon DH, Kuntz KM. Should postmenopausal women with rheumatoid arthritis who are starting corticosteroid treatment be screened for osteoporosis? A cost-effectiveness analysis. Arthritis Rheum. 2000;43:1967-75.

54. Tosteson AN, Rosenthal DI, Melton $\sqcup$ 3rd, Weinstein MC. Cost effectiveness of screening perimenopausal white women for osteoporosis: bone densitometry and hormone replacement therapy. Ann Intern Med. 1990;113:594-603.

55. Tsevat J, Durand-Zaleski I, Pauker SG. Cost-effectiveness of antibiotic prophylaxis for dental procedures in patients with artificial joints. Am J Public Health 1989;79:739-43.

56. Willis M, Odegaard K, Persson U, Hedbrant J, Mellstrom D, Hammar M. A cost-effectiveness model of tibolone as treatment for the prevention of osteoporotic fractures in postmenopausal women in Sweden. Clin Drug Invest. 2001:21:115-27.

57. Laupacis A, Bourne R, Rorabeck C, Feeny D, Wong C, Tugwell P, Leslie K, Bullas R. Costs of elective total hip arthroplasty during the first year. Cemented versus noncemented. J Arthroplasty. 1994;9:481-7. 